\title{
Fumigant activity of some essential oil against wheat weevil, Sitophilus granarius L. (coleoptera: curculionidae)
}

\begin{abstract}
The most important of the stored products pests is Sitophilus granarius L. (Coleoptera: Curculionidae). Chemical insecticides and fumigants are widely used to control $S$. granarius. In this study, fumigant effect of some essential oils was investigated against S. granarius. For this purpose, different concentrations essential oil of Mentha piperita L. (Lamiaceae), Citrus cienensis (L.), (Rutaceae) and Nigella sativa L. (Ranunculaceae) were used. Neem AzalT/s was used as a standard product. Glass jars were used for fumigant experiment. Each glass jar contained 50grams of wheat. Sponge pieces of $2 \times 3 \mathrm{~cm}$ size were cut and glued to the lower part of the jar lid. Then concentrations of $5 \%, 7 \%$ and $10 \%$ of each essential oil were applied on the sponge by an injector. For each solution $0.1 \mathrm{ml}$ was used. Twenty adults (1-3days old) were left in each of the jars. Afterwards the lids of the jars were tightly sealed and the jars were placed in the dark. The insects had no contact with the impregnated sponge. Control insects were kept under the same conditions without any application. Counts were carried out after 24 hours. Neem Azal ${ }^{\mathrm{TS}}$ was used by distilling with pure water. The results of the study showed that all the applied essential oils caused $100 \%$ death with the highest fumigant effect. In Neem Azal ${ }^{\mathrm{TS}}$ trial similar results were obtained as with essential oils.
\end{abstract}

Keywords: wheat weevil, essential oils, fumigant effect
Volume 9 Issue 2 - 202 I

Pervin Erdogan, Zemran Mustafa
Sivas University of Science and Technology, Turkey

Correspondence: Pervin Erdogan, Sivas University of Science and Technology, Faculty of Agricultural Sciences and Technology, Sivas, Turkey, Email pervinerdogan@sivas.edu.tr

Received: April 14, 2021 | Published: May 04, 2021

\section{Introduction}

Products grown by mankind are stored for short or long periods according to food, feed, marketing and objectives and post-harvest seed production depending on the needs of the region. During this period, significant losses occur in terms of quality and quantity due to pests, disease factors, birds and rodents and adverse environmental conditions. To explain this numerically; the rate of loss in stored grain, legume, oilseeds and foodstuffs made from them during the storage period is accepted as $10 \%$ worldwide. These losses reach up to $50 \%$ depending on the regions and characteristics. It is reported that $5 \%$ of this $10 \%$ loss in stored products is caused by insects. ${ }^{1}$ Product weight loss occurs as a result of pests feeding with stored products. In addition, the impurities and secretions formed as a result of their feeding create negative effects on the quality and quantity of the product. Moreover, the losses caused by the coexistence of more than one pest increase even more. The most important of the stored products pests is Sitophilus granarius L. (Coleoptera: Curculionidae). Feeding of $S$. granarius can also lead the grains to become vulnerable to the attack by other pests, by undermining their protection barrier which are otherwise are impenetrable to them. Females generally lay around 150 to 300 eggs. Their life cycle is completed in six weeks in warm weather and can be prolonged to 17-21 weeks in cold weather. The pest can cause up to $5 \%$ of losses in stored crops if not controlled. Feeding of S.garanarius on grains significantly reduces their germination capacity from $93 \%$ to $7 \%$. In addition, S.garanarius reduces the quality and quantity of the product. $^{2}$

In order to reduce this damage, chemical insecticides and fumigants are widely used to control stored product pests. Stored product insects, which are stored dry and adapted to plant products that are important in human nutrition, have an important place in the insect kingdom. These insects spread wherever the climatic conditions are favorable for them. The increase in international trade and the facilitation of intercontinental roundtrips have accelerated this spread even more. It is precisely known that many insect species harmful to stored products are of tropical or semi-tropical origin and were spread to other parts of the world through trade. Therefore, the fumigation process is cruc.ial. Widely used insecticides to prevent the damage of stored product pests cause resistance to these chemicals ${ }^{3}$ Researchers have focused on the development of alternative control methods against pests in stored products due to resistance development of pests and insecticide residue in products. In this context, plant-based insecticide developments have been accelerated considerably. ${ }^{4-6}$ Plant extracts and essential oils have some advantages such as low toxicity in mammals, no residue in the products and high toxicity to storage pests. ${ }^{7,8}$ This study was carried out to determine fumigant activity of some plant essential oils on $S$. granarius.

\section{Material and methods}

\section{Mass raring of test insects}

S. granarius culture was provided from Plant Protection Central Research Institute Ankara. For the stock culture of S. granarius 1/3 wheat was put into 21 t glass jars. Wheat's used in the study were kept at $-20^{\circ} \mathrm{C}$ for one week just before being used in the study in order to make them clean from any harmful infection. Adult individuals obtained from the stock culture were transferred to these jars and allowed to lay eggs for 48hours. At the end of this period, all adults were removed from the jars and only eggs and contaminated material remained. Adults were incubated for 45 days at $27 \pm 2^{\circ} \mathrm{C}, 50 \pm 10 \%$ relative humidity and dark conditions were used in the trials.

\section{Essential oil}

The essential oils (mint, orange peel, black seed, sesame and basil) were purchased from the local market. Different volumes of essential oils were dissolved in acetone fat test solution preparation (10,20 and 
$30 \mathrm{ml}$ dissolved in $1 \mathrm{ml}$ acetone). ${ }^{9}$ Neem Azal T/S was used as positive control. Neem Azal ${ }^{\mathrm{TS}}$ was purchased from the related company. It contains $1 \%$ azadirachtin and was obtained from $A$. indica.

\section{Fumigant effect of different plant extract}

Glass jars (1liter) were used for fumigant experiment. In each glass jar 50grams of wheat were put. Sponge pieces of $2 \times 3 \mathrm{~cm}$ size were cut and glued to the lower part of the jar lid. Then concentrations of $5 \%, 7 \%$ and $10 \%$ of each essential oil were applied on the sponge by an injector. For each solution $0.1 \mathrm{ml}$ was used. Twenty adults (13days old) were left in each of the jars. After that the lids of the jars were tightly sealed and the jars were placed in the dark. The insects had no direct contact with the impregnated sponge. Control insects were kept under the same conditions without any application. Counts were carried out after 24 hours. Four replicates were performed for each concentration and the untreated control. The experiment was set up according to the random plots and the trial pattern. These jars were placed in climatic cabin at $27 \pm 2^{\circ} \mathrm{C}$, and $50 \pm 10 \%$ humidity.

Neem Azal ${ }^{\text {TS }}$ was used by distilling with pure water. ${ }^{9}$

\section{Data analysis}

The effect was calculated according to Abbott. ${ }^{10}$ Variance analysis were applied to the obtained results and the mean values were compared by Duncan's test $(\mathrm{P}=0.05)$ calculated by the program SPSS 13.6. Mortality rate was calculated as follows:

Mortality=the number of died $S$. granaries adults after treatment / the number of $S$. granarius adults before treatment $\cdot 100$.

\section{Results and discussion}

\section{Fumigant effect of different plant extract}

The data obtained as a result of the fumigant experiments are given in Table 2. According the Table 2, the highest fumigant effect was determined in the highest concentrations of different essential oils. Also, the lowest fumigant effect was determined in the first concentration of different essential oils. Similar results were obtained in the mortality rate. According to the statistical analysis, the second and third concentrations of all different plant essential oils were in the same group. First concentration of $C$. cienensis, $N$. sativa and Neem Azal T/S formed different groups. The first concentration of $M$. piperita was in a different group $(\mathrm{F}=43.65)(\mathrm{P}<0.05)$. All essential oils tested showed strong fumigant effect against $S$. granarius. In particular, $100 \%$ mortality was obtained at the second and third concentrations of all oils. In the first concentration, low mortality was obtained. The results are in tone with the findings of Cam et al. ${ }^{11}$ who studied that the essential oil of different Mentha species (M. spicata, M. villosonervata, M. piperita) showed fumigant toxicity against granary weevil. In addition, it was revealed that the essential oils of mint species (Mentha spp.) had adulticidal, larvicidal, and growth and reproduction inhibitory effects, as well as repellent activity against various stored product pests and vectors. ${ }^{5,12,12}$ Also, Kimbaris et al. ${ }^{14}$ demonstrated that essential oil of $M$. piperita has strong fumigant toxicity against greenhouse pests such as Trialeurodes vaporariorum, Tetranychus urticae and several aphid species. In another study the extract of $M$. piperita was found to cause $63 \%$ mortality on Sitophilus oryzae L. and $44.33 \%$ on Tribolium castaneum. ${ }^{15}$ In another study, Karamaouna et al. ${ }^{16}$ reported that the essential oils of peppermint had more toxic to Planococcus ficus (Signoret) (Hemiptera: Pseudococcidae). According to results of GC/MS major components were found to be camphane (14.01\%), menthone (13.89\%), menthol (12.37\%) $\beta$-pinene (7.62\%), pulegone (6.41\%), $\beta$-cubebene (4.95\%), $\alpha$-pinene $(4.743 \%)$, $\gamma$-terpinene (4.08\%), delta-carane (3.81\%), and piperiton (3.04\%). ${ }^{17}$ Species belonging to the Mentha genus in particular monoterpenes have previously shown high fumigant activity against storage pest species. ${ }^{5,18}$ Abdelgaleil et al. ${ }^{19}$ determined that the main components of vegetable essential oils showed contact and fumigant effects on $S$. oryzae and T. castaneum. Oodeyemei et al. ${ }^{20}$ revealed that essential oils have high repellant activity at all concentrations tested. For most concentrations, repellency values of as high as $100 \%$ were recorded making Mentha longifolia a potential agent to use as protection of stored agricultural products against $S$. zeamais.

Table I Names and families of the plants used in the experiment

\begin{tabular}{ll}
\hline Plants name & Family \\
\hline Mentha piperita L. & Lamiaceae \\
Citrus cienensis (L.) & Rutaceae \\
Nigella sativa L. & Ranunculaceae \\
\hline
\end{tabular}

Table 2 Fumigant effect of some plants essential oil on Sitophilus granarius $\mathrm{L}$

\begin{tabular}{|c|c|c|c|}
\hline \multirow[t]{2}{*}{ Treatment } & \multirow[t]{2}{*}{ Conc. (\%) } & \multicolumn{2}{|c|}{ After $24 \mathrm{~h}$ exposure } \\
\hline & & $\begin{array}{l}\text { Adult } \\
\text { mortality (\%) }\end{array}$ & Effect (\%) \\
\hline \multirow{3}{*}{ Mentha piperita L. } & 5 & 42.50 & $43.09 \pm 0.90 c^{*}$ \\
\hline & 7 & 100.00 & $100.00 \pm 0.00 \mathrm{a}$ \\
\hline & 10 & 100.00 & $100.00 \pm 0.00 \mathrm{a}$ \\
\hline \multirow{3}{*}{ Citrus cienensis (L.) } & 5 & 51.25 & $50.65 \pm 1.45 \mathrm{~b}$ \\
\hline & 7 & 100.00 & $100.00 \pm 0.00 \mathrm{a}$ \\
\hline & 10 & 100.00 & $100.00 \pm 0.00 \mathrm{a}$ \\
\hline \multirow{3}{*}{ Nigella sativa L. } & 5 & 63.75 & $63.35 \pm 0.60 \mathrm{~b}$ \\
\hline & 7 & 100.00 & $100.00 \pm 0.00 \mathrm{a}$ \\
\hline & 10 & 100.00 & $100.00 \pm 0.00 a$ \\
\hline \multirow{4}{*}{ Neem Azal T/S } & 0.1 & 86.25 & $86.05 \pm 1.00 \mathrm{a}$ \\
\hline & 0.2 & 100.00 & $100.00 \pm 0.00 \mathrm{a}$ \\
\hline & 0.3 & 100.00 & $100.00 \pm 0.00 \mathrm{a}$ \\
\hline & Control & 0.012 & \\
\hline
\end{tabular}

*Within columns, means \pm SE followed by the same letter are not significantly different (DUNCAN's multiple F-test)

Our results showed that essential oil of $C$. cienens caused the highest mortality at rate highest concentrations $(7 \%$ and $10 \%)$. The present findings are similar to the reports of Zewde \& Jembere, ${ }^{21}$ where they found the essential oil of orange peel was toxic to Zabrotes subfasciatus (Coleoptera: Bruchidae). It is stated in the same study that the essential oil of orange peel has fumigant and repellent effect on Z. subfasciatus. Also, this essential oil had the highest mortality and protectant effect on $Z$. subfasciatus. Tripathi et al. ${ }^{22}$ reported that essential oil from orange peels is known to have toxic, feeding deterrent, and cause poor development effects on lesser grain borer, Rhyzoperta domonica (F.), rice weevils, Sitophilus oryzae (L.) and red floor beetle, Tribolum castaneum (Herbst). Additionally, the peel oil showed toxic effect to Culex pipiens ${ }^{23}$ and cow pea weevils, Callosobruchus maculates (F.). ${ }^{24}$ Furthermore, the peel oil has fumigant action toward fleas ${ }^{25}$ and house hold insects Blatella germanica $(\mathrm{L}$. and Musca domestica (L.) and stored product Sitophilus. ${ }^{26}$ As it is seen in our study results, the fumigant effect has increased with the 
increasementin concentrations. In all treatments, higher mortality rate was observed at high concentrations compared to low concentrations. The present results agree with previous research published by Tripathi et al. ${ }^{22}$ who found that the orange peel oil has 13 times higher fumigant toxicity than that of methyl bromide. Keita et al. ${ }^{27}$ described that the mode of the action of fumigant toxicity of essential oil against insects might be due to the inhibition of acetylcholinesterase.

According to the results obtained in our study, the highest concentrations of $N$. sativa showed $100 \%$ mortality on S. garanarius. The similar results were also obtained by Bekinwari \& Roate ${ }^{28}$ who reported that seed powder of $N$. sativa had insecticidal effect on Dermestes maculatus De Geer (Coleoptera: Dermestidae). Rasool et al. $(2018)^{29}$ reported that different concentrations of $N$. sativa had insecticidal effect against Rhyzopertha dominica F. (Col. Bostryshidae). N. sativa composed of styrol, thymoquinone and p-cymene, were effective on mosquitoTand that hese substances can be used to control mosquitoes in the future. ${ }^{30}$ Concentration of $25 \mathrm{mg} /$ $\mathrm{ml}$ black cumin in empty space induced nearly $100 \%$ mortality. On the other hand, fumigation in space filled up with $50 \%$ wheat showed only $50 \%$ to $60 \%$ killing efficiency against granary weevil. In space $95 \%$ filled up with wheat mortality was found to be only $34 \%{ }^{31}$ In another study, Ghoneim et al. ${ }^{32}$ demonstrated that seed extracts of $N$. sativa showed inhibitory effects on the oviposition efficiency and other parameters of reproductive potential of the desert locust Schistocerca Gregaria (Orthoptera: Acrididae). In the same study, it was revealed that the majority of $N$. sativa extracts caused several morphological and intracellular disorders in some hemocytes.

Moreover, it was stadied that $N$. sativa seed extracts affected negatively the vitelline envelope formation or the function of follicle cells or caused an adverse effect on the morphogenesis of ovipositor of adult females, ovarian growth and/or synthesis and metabolism of proteinaceous constituents during the oogenesis on S. Gregaria. ${ }^{33,34}$ $N$. sativa seeds have medicinal properties such as bronchodilatory, hypotensive, antibacterial, antifungal, analgesic, anti-inflammatory and immunopotentiating. ${ }^{35} \mathrm{~N}$. sativa had acaricidal effect and caused $100 \%$ mortality at concentration $20 \%$ in shortest time $(12 \mathrm{~h})$ on Rhipicephalus annulatus (Acari: Ixodidae). ${ }^{36}$ In addition, Zeeshan and Mazhar $^{37}$ revealed that essential oil of $N$. sativa showed insecticidal effect as high as $44.44 \%$ at concentration of $10 \%$ after 1 week on $R$. dominica. The essential oil of $N$. sativa seeds contains compounds that repellent Anopheles gambiae Giles (Diptera: Culicidae) and therefore can be used to control spread of malaria through prevention of the insect bites. Similarly, it was demonstrated that essential oil of $N$. sativa showed the highest fumigation and repellent effect on Tribolium castaneum Herbst (Coleoptera: Tenebrionidae. ${ }^{9}$ In the same study, it was reported that essential oil of $N$. sativa has strong repellent effect on $T$. castaneum. The essential oil of seed of $N$. sativa had insecticidal and insect repellent activities. ${ }^{38-40}$

There are also many studies on azadirachtin obtained from Azadirachta indica A. Juss (Meliaceae). For example, Kavallieratos et al. ${ }^{41}$ reported that azadirachtin-based insecticides, NeemAzal-T/S had the highest mortality on $T$. confusum. S. oryzae. Tofel et al. ${ }^{42}$ demostrated that $A$. indica oil showed the highest mortality on $C$. maculatus and Sitophilus zeamais. Azadirachtin acts as an insect growth regulator. This might have contributed in progeny production suppression. ${ }^{42}$ Athanassiou et al. $^{44}$ reported that Azadirachtin A of NeemAzal-T/S caused $100 \%$ mortality to Sitophilus oryzae (L.) (Coleopera: Curculionidae). Neem products are rich in alkaloids (azadirachtin) and other molecules like nimbine, salanine and melandriol, which reduce feeding, through chemoreception (primary anti-feedant) after ingestion, These molecules play role in blocking the input from receptors that normally respond to phagostimulants, or from stimulation of specific deterrent cells or both. ${ }^{45}$

\section{Conclusion}

Our findings revealed that the essential oil of $M$. piperita, $C$. cienensis, $N$. sativa and commercial product Neem Azal T/S had strong fumigant effect on $S$. granarius. Further studies are needed to be conducted to use these oils to control $S$. granarius.

\section{Funding}

None.

\section{Acknowledgments}

None.

\section{Conflicts of interest}

The author declares that there is no conflict of interest.

\section{References}

1. Prevett PF. Stored products pests causing losses of stored food. FAO Plant Protection Bulletin. 1975;234/5:115-117.

2. Boniecki P, Piekarska-Boniecka H, Świerczyński K, et al. Detection of the granary weevil based on X-ray images of damaged wheat kernels. Journal of Stored Products Research. 2014;56:38-42.

3. Lee B, Choi WS, Lee AS, et al. Fumigant Toxicity of essential oils and their constituent compounds towards the rice weevil, Sitophilus oryzae (L.). Crop Protection. 2001;20:317-320.

4. Nagahban M, Moharramipur S, Sefidkon F. Fumigant Toxicity of essential oil from Artemisia sieberi besser against three stored product insects. Journal of Stored Products Research. 2007;43(2):123-128.

5. Rajendran S, Sriranjini V. Plant products as fumigants for stored-product insect control. Journal of Stored Product Research. 2008;44:126-135.

6. Chu SS, Liu QR, Liu ZL. Insecticidal activity and chemical composition of the essential oil of Artemisia vestita from China against Sitophilus zeamais. Biochemical Systematics and Ecology. 2010;38(4):489-492.

7. Sahaya E, Kosyukovski M, Eilberg J, et al. Plant oils as fumigants and contact insecticides for the control of stored product insects. Journal of Stored Products Research. 1997;31:291-299.

8. Rozman V, Kalinovic I, Liska A. Bioactivity of 1,8-cineole, camphor and carvacrol against rusty grain beetle (Cryptolestes ferrugineus Steph.) on stored wheat, 687-694. In: Proceedings of the Ninth International Working Conference on Stored Product Protection; Sao Paulo. 2006. p.1359.

9. Chaubey MK. Insecticidal activity of Trachyspermum ammi (Umbelliferae), Anethum graveolens (Umbelliferae) and Nigella sativa (Ranunculaceae) essential oils against stored-product beetle Tribolium castaneum Herbst (Coleoptera: Tenebrionidae). African Journal of Agricultural Research. 2007;2(11):596-600.

10. Abbott WS. A method of computing the effectiveness of an insecticide. Journal Economic Entomology. 1925;18(2):265-267.

11. Cam H, Karakoc OC, Gokce A, et al. Fumigant toxicity of different mentha species against granary weevil [Sitophilus granarius L. (Coleoptera: Curculionidae)]. Turkish Journal of Entomology. 2012;36(2):255-263.

12. Kumar P, Mishra S, Malik A, et al. Insecticidal properties of Mentha species: A review. Industrial Crops and Products. 2010;34:802-817.

13. Michaelakis A, Papachristos D, Kimbaris D, et al. Larvicidal evaluation of three Mentha species essential oils and their isolated major components against the West Nile virus mosquito. Hellenic Plant Protection Journal. $2012 ; 4: 35-48$ 
14. Kimbaris AC, Papachristos DP, Michaelakis A, et al. Toxicity of plant essential oil vapours to aphid pests and their coccinellid predators Biocontrol Science and Technology. 2010;20:411-422.

15. Kathirvelu C, Raja SR. Efficacy of Selected Plant extracts as insecticidal fumigant against Certain stored grain insect pests under laboratory conditions. Plant archives. 2015;15(1):259-266.

16. Karamaouna F, Kimbaris A, Michaelakis A, et al. Insecticidal Activity of Plant Essential Oils Against the Vine Mealybug, Planococcus ficus. Journal Insect Science. 2013;13:142.

17. Golparvar AR, Hadipanah A. Chemical compositions of the essential oil from peppermint (Mentha piperita L.) cultivated in Isfahan conditions. Journal of Herbal Drugs. 2013;4(2):75-80.

18. Lopez MD, Pascual-Villalobos MJ. Mode of inhibition of acetylcholinesterase by monoterpenoids and implications for pest control. Industrial Crops and Products. 2010;31:284-288.

19. Abdelgaleil S, Mohammed M, Badawy M, et al. Fumigant and contact toxicities of monopertenes to Sitophilus oryzae (L.) and Tribolium castaneum (Herbst) and their inhibitory effects on acetylcholinesterase activity. Journal of Chemical Ecology. 2009;35:518-525.

20. Odeyemi OO, Masika P, Afolayan AJ. Insecticidal activities of essential oil from the leaves of Mentha longifolia L. subsp. capensis against Sitophilus zeamais (Motschulsky) (Coleoptera: Curculionidae). African Entomology. 2009; 16(2):220-225.

21. Zewde DK, Jembere. Evaluation of Orange Peel Citrus Sinensis (L) as a Source of Repellent, Toxicant and Protectant against Zabrotes Subfasciatus (Coleoptera: Bruchidae). Momona Ethiopian Journal of Science. 2010;2(1):61-75.

22. Tripathi AK, Prajaoati V, Khanuja SP, et al. Effect of d-Lemonene on three stored-product beetles. Journal Economic Entomology. 2003;96:990-995.

23. Mwaiko GL, Savaeli ZX. Citrus peel oil extracts as mosquito larvae insecticides. East Africa Medical Journal. 1992;69:223.

24. El-Sayed F MA, Abdel-Razik M. Citrus oil as protectant against infestation by Callosobruchus maculatus (F.) (Coleoptera:Bruchidae). Bulletin Entomology Society of Egypt Economics. 1991;14:423-427.

25. Weinzierl R, Henn T. Alternatives in insect's management: Biological and Biorational Approaches. University of Illions, Urban-Champaign. North Regional Extention Publication. 1992;401

26. Karr LL, Coast J. Insecticidal properties of d-limonene. Journal Pesticides Science. 1988;13:287-290.

27. Keita SM, Vincent C, Schmit J, et al. Efficacy of essential oil of Ocimum basilicum L. and O. gratissimum L. applied as an insecticidal fumigan and powder to control Callosobruchus maculates (Fab.) (Coleoptera: Bruchidae). Journal Stored Products Research. 2001;37:339-349.

28. Bekinvari BM, Boate UR. Insecticidal property of Black Seed (Nigella sativa) Powder as an Eco-frendly Management of Skin Beetle Dermestes maculatus (Coleoptera:Dermestidae) in Atlantic Codfish Gadus morhua ( Godformes:Gadidae). Asian Journal Advances in Agricultural Resarch. 2020;13(3):47-56.

29. Rassol A, Ali Z, Mazhar U, et al. Insecticidal impact of Kalonji (Nigella sativa) as Bio-pesticide. National Agriculture Research Center. Islamabad. 2018 .
30. Wijayanti F, Naim M, Sina I. Analysis of black seed effect on Aedes aegyptii. International Journal of Zoological Research. 2019;15(1):1320.

31. Karakas M, Bolukbasi E. Bio-insecticide effect of black cumin against Granary weevil, Sitophilus granarius L. (Coleoptera: Curculionidae) on stored wheat. International Journal of Entomology Research. 2017;2(4):38-40.

32. Ghoneim K, Hamadah Kh, El-Hela A, et al. Inhibitory Effects of Nigella Sativa (Ranunculaceae) Extracts on the Reproduction of Desert Locust Schistocerca gregaria (Orthoptera: Acrididae). International Journal of Research Studies in Zoology. 2015;1(1):43-55

33. Di Ilio V, Cristofaro M, Marchini D, et al. Effects of a neem compound on the fecundity and longevity of Ceratitis capitata (Diptera: Tephritidae). Journal of Economic Entomology. 1999;92:76-82.

34. Lucantoni L, Giusti F, Cristofaro M, et al. Effects of a neem extract on blood feeding, oviposition and oocyte ultrastructure in Anopheles stephensi Liston (Diptera: Culicidae). Tissue Cell. 2006;38:361-371.

35. Khan MA, Afzal M. Chemical composition of Nigella sativa Linn: Part 2 Recent Advances. Inflammopharmacol. 2016;24:67-79.

36. Aboelhadid SM, Mahran HA, El-Hariri, et al. Rhipicephalus annulatus (Acari: Ixodidae) Control by Nigella sativa, Thyme and Spinosad Preparations. Journal of Arthropod-Borne Diseases. 2016;10(2):148-158

37. Zeeshan A, Urooj M. Toxic effects of Nigella sativa against Rhyzopertha dominica (Coleoptera: Bostrichidae). Journal of Agricultural Science and Botany. 2018;2(4):3-6.

38. Ahmed AM. A dual effect for the black seed oil on the malaria vector Anopheles gambiae: Enhances immunity and reduce the concomitant reproductive cost. Journal Economic Entomology. 2007;4(1):1-19.

39. Raj GA, Chandrasekaran M, Krishnamoorthy S, et al. Phytochemical profile and larvicidal properties of seed essential oil from Nigella sativa L. (Ranunculaceae), against Aedes aegypti, Anopheles stephensi, and Culex quinquefasciatus (Diptera: Culicidae). Parasitology Research. 2015;114:3385-3391.

40. Wijayanti F, Naim M, Sina I. Analysis of black seed effect on Aedes aegyptii. International Journal of Science and Research. 2019;15(1):1320.

41. Kavallieratos N, Athanassiou C, Saitanis CJ, et al. Effect of Two Azadirachtin Formulations against Adults of Sitophilus oryzae and Tribolium confusum on Different Grain Commodities. Journal of Food Protection. 2007;70(7):1627-1632.

42. Tofel KH, Nukenine EN, Stacher M, et al. Degradation of azadirachtin A on treated maize and cowpea and the persistence of Azadirachta indica seed oil on Callosobruchus maculatus and Sitophilus zeamais. Journal of Stored Products Research. 2016;69:207-212.

43. Chaudhary S, Kanwar KR, Cahili DM, et al. Progress on Azadirachta indica Based Biopesticides in Replacing Synthetic Toxic Pesticides. Frontiers in Plant Science. 2017;8:610.

44. Athanassiou CG, Kontodimas DC, Kavallieratos NG, et al. Insecticidal effect of NeemAzal against three stored-product beetle species on rye and oats. Journal of Economic Entomology. 2005;98:1733-1738.

45. Schmutterer H. Properties and potential of natural pesticides from the neem tree, Azadirachta indica. Annual Review of Entomology. 1990;35:271-297. 